\title{
Catching life:
}

\section{The contribution of arts initiatives to recovery approaches in mental health}

\author{
Helen Spandler, Jenny Secker, Lyn Kent, Suzanne Hacking and Jo \\ Shenton
}

\section{Introduction: recovery and mental health}

It is increasingly recognized that with appropriate support, people with even the most severe and enduring mental health problems can recover. In some cases this refers to a clinical sense of an absence of symptoms, and in others in the more social sense of recovering a fulfilling life, regardless of mental health diagnosis. Indeed, the so-called chronicity of mental health problems is not necessarily connected to the inherent course of a defined category of illness, but rather with the quality of a person's life in society. Thus, recovery is not necessarily predicated on a biomedical notion of 'recovery from illness' or 'remission of symptoms' (although this is often how it is interpreted). Notions of recovery have been inspired by services users' accounts of their own recovery journeys that have occurred with, without or sometimes despite, specific mental health interventions (Deegan 1990, Coleman 1999; http://www.soterianetwork.org.uk).

In this context, we have seen the emergence in the last 15 years of what has been called a recovery approach to mental health in the UK, North America, Australia and New Zealand. This notion of 'recovery' has been embraced by some sections of the service user movement and, to some degree, practitioners and policy drivers. However, recovery has been increasingly contested and its conflation - in policy and practice - with paid employment and social inclusion have raised some concerns (Spandler 2007). In addition, the study of recovery can be problematic because there is no agreed-on conceptual model to guide research design and methodology. There is, for example, no clear consensus within the mental health community about what people are recovering from, what the process of recovery is, nor what the outcomes of recovery should be.

Notwithstanding these difficulties, we use the notion of recovery in this chapter to refer to a user-centred and primarily social ideal. This may, or may not, involve symptom reduction, use of services, diagnosis or medication, but does involve the individual moving towards being able to live the kind of life she or he wants to live. In this sense, recovery can be seen as the long-overdue emergence of a 'social model' within mental health (Beresford; 2000, Ramon 2003). This is because it challenges the traditional way of providing mental health support and instead focuses on social conditions and the importance of having the necessary assistance to be able to pursue one's own self-defined goals and aims. Arguable, this approach circumvents sterile arguments between competing intervention and 
treatment models by working within the service user's own frameworks, definitions and understandings of their difficulties and aspirations (Repper \& Perkins 2003).

\section{Key components of recovery}

A user-centred ideal of recovery, by definition, should not impose particular norms of what recovery means for people, but should where possible, prioritise individually defined accounts and goals (within their particular social context). Having said that, there are a number of commonly agreed components which seem to be necessary for processes of recovery and which are subjective enough to keep this individuated notion at its core.

Feelings of despair and hopelessness are often key features of long-term mental health difficulties and use of mental health services. Hopelessness is a predictor of poor long-term outcomes (Aguilar et al. 1997) and suicide (Drake \& Cotton 1986, Beck et al. 1990). This hopelessness is often exacerbated by the low expectations and therapeutic pessimism of services as well as by the stigma and discrimination frequently associated with mental health difficulties (Dunn 1999). In this context, hope is viewed as a 'life saving force' (Russinova 1999) and recovery can be viewed as a reawakening of hope after despair (Ridgway 2001). The importance of having a sense of hope for the future has, therefore, been identified as an essential factor across the literature (Adams \& Partree 1998, Pitt et al. 2007).

Hope is often seen to involve the anticipation of a future based upon mutuality, a sense of personal competence, coping ability, psychological wellbeing, purpose and meaning in life, as well as a sense of 'the possible'. In this way, hope could be an overarching theme in recovery as these factors relate to other components commonly referred to in the literature. For example, having a sense of purpose and meaning is frequently considered central to recovery (Turner-Crowson \& Wallcraft 2002). In addition, the development of coping strategies and self-management of mental health problems are also viewed as important (Ridgway 2001, Onken et al. 2002). Finally, the importance of social support and the rebuilding of identities beyond mental ill health has also been recognised (Repper \& Perkins 2003).

Art participation and creativity often features in anecdotal and individual recovery journeys, and research suggests that participatory art does have a range of positive therapeutic benefits for people with mental health needs (Heenan 2006). However, there has been limited research which explores the importance of arts activities as contributing to notions of a social model of recovery, at least in the sense described above. Therefore, the rest of this chapter draws on the qualitative findings from a recent national research study which was conducted by the authors (Secker et al. 2007). We use this to explore how arts and mental health projects can facilitate some of these key elements in a recovery approach to mental health.

\section{National Arts and mental health study}

This national study was jointly funded by two government bodies in England, the Department for Culture Media and Sport and the Department of Health. 
The study comprised a number of strands of research, including a survey of arts projects that resulted in a 'mapping' of arts and mental health activity in England (Hacking et al. 2006); a 6-month follow-up survey of arts participants using standardized outcomes measures relating to mental health, social inclusion and empowerment (Secker et al. 2008); and a series of qualitative case studies, which are our focus here.

For the case studies, we selected six diverse arts and mental health projects to explore the processes though which arts projects achieved benefits for participants. These included an 'arts on prescription' project, which offers short art courses to people experiencing mainly depression and anxiety associated with distressing life events or pressures (project 1); a studiobased project in which people with severe and enduring needs, often related to experiences of abuse, are able to work together to develop their creativity and develop and exhibit their artwork (project 2); a rural community organization facilitating workshops and projects for vulnerable, isolated groups, including people with a range of mental health needs (project 3); an arts project which is part of an Asian women's mental health organization providing culturally relevant opportunities, including arts and crafts, through which women can gain support from each other (project 4); a Mind day centre offering art as part of a range of activities aimed at providing a structure for developing social interaction with others for people with severe mental health needs (project 5 ); and a college-based project offering flexible arts-based courses for people with mental health needs at the college and in local mental health facilities (project 6).

We carried out individual in-depth interviews with 34 arts project participants. The interviewees were between the ages of 35 and 78 years and had been involved with the projects for between 4 months and 5 years. Twenty-nine were of white British ethnicity and five were South Asian women. The interview questions focused on participants' expectations of their project, what they saw as the benefits, how they thought any benefits had come about and specifically whether participation in arts (rather than other activities) was important in achieving them. The interviews lasted between an hour and an hour and a half and were all recorded and transcribed. Interview data were analysed by two members of the research team working independently and then comparing notes in an iterative process to agree and refine an account of 'what worked' for participants and the mechanisms involved in achieving any benefits. The data were then reviewed and subjected to a further thematic content analysis to identify key themes from participants' accounts of the impact of arts participation in relation to the key features of 'recovery' as defined above.

\section{Themes from the case studies}

Most participants across all six projects reported how arts participation had increased their motivation by enabling them to gain inspiration to engage with their artwork. It was clear that this process, alongside developing their artistic abilities and belief in themselves, helped participants to gain a sense of purpose and meaning in their lives: 
Eventually over time doing a little bit and a little bit and being able to come in here and getting that little bit better, there's a slow progression of being able to do things and it gives you some kind of positive purpose in life ... that little something has a positive effect on me, mentally ... it presses my creative button I suppose (project 5, participant 5).

Before I didn't think I could do it, whereas now I know I can, I'm a completely different person ... now I want to go and do things ... Focusing on creativity means you've got like a little reason for doing things (project 6, participant 3).

This sense of purpose was not confined to their artwork but often enabled participants to have more purpose and direction in the rest of their lives:

I feel when I come that I have got some purpose . . . Coming here gives me impetus to make the rest of my time more important... It gives me something to look forward to (project 6, participant 1).

For participants who did not have a background in art, this was often related to arts participation enabling them to becoming aware of their latent abilities, especially around their awareness and sensory perception. Some of these participants reported being able to use their new artistic abilities to find meaning in the local and natural environment:

It was a nice spring day and I picked up my pad and I took my little fold up garden chair and I just . . . went down with a drink and a sandwich and I drew. I was on my own and I did it and that was just brilliant so I think I will do more of that now ... I am getting more confident now to actually sit on my own and do this because 
and this is where it is helping me ... I am going to actually take it out of what I am doing in the class (project 1, participant 4).

For the following participant, having a greater sense of purpose and meaning in her life was especially important in the context of having taken early retirement as a result of her mental health difficulties:

Feeling and doing these small things, [I get a] a kind of excitement that my life at whatever level can have meaning ... and it's important as you get older that you feel you have value (project 1 , participant 2 ).

It is perhaps not surprising that art has the potential to enable people to find purpose and meaning in their lives because of the way that arts projects are often able to support participants to discover individual sources of meaning and value through their artwork and through the active creation of something unique and new:

It doesn't matter if your leaf or a flower doesn't look like a leaf or a flower, it's your leaf and your flower and it's your expression of what's inside you, and I think that's a good thing, because all of us can only get better by facing ourselves and what's inside and working on our own stuff, and not judging ourselves either and truly saying to ourselves, 'well this is where I am, this is what I've been through, this is where I'll start'. And I can do something with my life (project 1 , participant 2).

Having a sense of purpose and meaning also enhanced participants' ability to engage in other aspects of their lives. For many participants, art had become an activity that they were able to pursue elsewhere, usually at home. For some, increased motivation had led to an expansion of their creative repertoire though the taking up of additional new interests outside the project, such as music lessons, creative writing or computers. Several participants also reported taking their art with them on holiday or doing creative activities at home with their family. Many participants made an explicit link between the growing hope and aspirations inspired by their 
creative activities and decreased levels of hopelessness, which, as we have seen, is an important factor in 'recovery':

It gives me a destination . . . Without it I would be very depressed, it gives something to aim for and stay in touch and keep going on for . . . It enthuses me where I wouldn't otherwise have, I know I wouldn't (project 6, participant 6).

It's an ignition, it's a spark . . . What happens is when they've ignited me a little bit here I go home and I stay on that creation. If you are creating things you don't get depressed (project 3, participant 2).

Many participants referred to their engagement in arts activities as improving their motivation and inspiration. At one of the projects, all six participants reported having increased the days they attended the project, even though it meant having to pay for themselves. They explicitly related this to their growing motivation to develop their artwork, which was particularly striking as all had clearly described how unmotivated and pessimistic they had been, both about the project and the future, before they started attending the project.

It's actually given me back in my life some ambition to do something. Which is something that had been absent for a very long time (project 2, participant 3 ).

Only a minority of participants actually reported taking up new formal opportunities in the world (what may be seen as 'hard outcomes' in relation to, for example, social inclusion or employment). However, most participants did describe often quite profound increases in their personal aspirations. Widening aspirations should not be underestimated because a broadening of the horizons of people's lives beyond the world of mental health services is such an important aspect of the journey towards recovery. The aspirations described by participants revolved around the world of art, work and education:

It does spur you on to consider that, either it's a hobby 
that you take up and you can use that in a positive way, or you can decide that perhaps you're good enough to want to go and work in that sort of field ... This art project I must admit has inspired me to think that perhaps I could do something in textiles and things like that (project 5, participant 5).

Gradually, it's through this, gradually I'm starting to get back into the big wide world again. I don't find it so scary ... I don't know what it is, it gives you something. It gives you a reason to get up on the morning, it makes you think, 'well if I can do this two days a week, maybe I can do a job' (project 2, participant 2).

Another important aspect of recovery is often the development of coping strategies. There were three different ways in which arts participants reported being able to use art projects to help them develop new or alternative coping strategies. These related to three processes we identified as being important for individuals in gaining benefits from the projects. First, most of the participants reported how arts activities enabled them to relax and 'ground' themselves by focusing on something specific and absorbing. This seemed to enable them to develop ways of dealing with distress, by focusing on something outside of themselves. A small number of participants across different projects described how concentrating on art helped reduce the distressing impact of voices or visions:

While I'm painting I'm not listening to the voices I'm hearing, I'm not trying to reply to them, they're forced into the background almost as a distraction because you're involved with something . . . and I think also when I'm painting I find a rhythm to it (project 2, participant 1 ).

A number of participants also reported that the focus and concentration involved in art had a positive impact in relation to their self-harm. Many people who self-harm describe this as a need to focus their emotional pain onto something physical and tangible which gives them a break from difficult thoughts, feelings and memories. Some participants were able to transfer 
this onto their art, which gave them an alternative way of dealing with distress:

It was a 'stop-gap' in a way but it kept me going, it took my mind off doing more harmful things [to myself] and that eased off how bad I felt, the intensity sort of eased off. So it's a preventative sort of measure in a way and it helped me for a period of time (project 2, participant 5).

Another participant recalled how she was able to recreate the memory of the effect gained from focusing on art, suggesting that the more she was able to achieve this effect the easier it was to recreate:

You can only do it for so long and you are bound to come back to it but at least it can give you a break . . . sometimes it stops it just building up into that, you know, 'I can't escape' feeling, if you can just break it. Once you have been there it is easier to get back to it (project 1, participant 5).

The lasting effect of focusing on art described by participants was linked for several people with the 'portability' of their art. This was particularly the case for people who were beginning to use art in the rest of their lives as a way of deflecting or focusing them away from problems. The following participant was able to use art at home to help him cope with the distress of hearing voices, which in the past he had coped with through self-harm:

Once I've lost myself in the artwork the problems in my head just disappear, they just alleviate and just leave me feeling better . . . I can use it as a good distraction now to free me up from my head . . . I used to be distracted by voices. Even though I was on medication to stop it sometimes they'd still come through and distract my days or bring me just right down to the point where I'd cut [myself]. Now, as a distraction, if I feel I'm getting 
like that, I'll try and draw what I'm feeling on paper so

that I can actually visualise it and see it, and then I'll set

fire to it and then I've got rid of it, I've killed it, it's gone

(project 5, participant 2).

Some of the arts projects enabled participants to find new ways of coping with distress, through self-expression, for example by re-creating painful images, creating more positive images, or expressing difficult feelings directly onto their artwork and/or through the process of making art. The art projects enabled them to make their difficulties more visible to themselves and others, and gave them a way of relating to their experiences in new and different ways. This helped to make their difficulties easier to cope with and also gave them an alternative means of coping with their distress. Selfexpression seemed to be particularly beneficial for individuals who were struggling with issues such as self-harm and hearing voices that were related to past experiences, for example of abuse and bullying:

If you've got lots of crap going on in your head and you're thinking 'god I can't cope with this', the voices are strong or something or you just can't cope. It's just good to get it out on paper ... the voices . . . its a way of saying 'I'm not going to cope with you today' ... It helps you get shit out of your head when you feel you can't cope... . Even if you chuck it away afterwards you know at least you've got it out on a piece of paper and you can look at it and say 'well that's that piece of shit!' And then you've got it all on a piece of paper and you can sort it all out in your head and get it in some sort of order. You can sort it all out in your head seeing it on paper just makes sense of it

(project 3, participant 1).

If I have a vision like that, I can put it straight into my artwork, so a lot of the things I am seeing or experiencing are coming out in my painting ... So I have found it easier to deal with the things I'm seeing .... It has given me an emotional visualistic and creative outlet . . . It takes the edge off any bad visions... Sometimes if I find if $I^{\prime} m$ in a bit of a state . . . then I find it easier to draw 
that out and exorcise my demons so to speak (project 6, participant 5).

For many participants, the self-expression facilitated by their arts project contrasted with experiences of feeling out of control, of being controlled by others or by circumstances:

I think it's because my life is so restricted now ... .

Because you know, that's a good word, control. I feel

like my life is controlled through no fault of my own, so

much that to suddenly have that freedom, it just released something inside of me (project 1 , participant 4 ).

Arts participation was related for some participants with the process of rediscovering or rebuilding an identity within and beyond that of someone with mental health difficulties, again an important element of recovery. Because building identities is in large part a social process, involving internalization of the perceptions of others (Howarth 2003), the process was especially associated with opportunities to create and display a finished artwork. Creating a finished work of art made participants' achievements visible to themselves, in turn enabling them to see themselves as someone who could achieve something. This was frequently mentioned across all six projects. Participants often referred to the importance of feeling valuable and worthwhile, especially in relation to others.

Arts participation helped some participants strengthen or realign their selfimage in relation to others, including family, friends and the local community, because they felt people began to see them as having artistic talents and viewed them differently as a result. Manifestations of this change included participants' artwork being welcomed by their families and friends. Other participants spoke of requests for artwork to be displayed in community venues, of being able to teach art skills to others, and of families or friends making great efforts to support their arts activity. In addition, eight participants described an even more profound change, above and beyond being seen as someone with some artistic ability, in that the production of artwork enabled them to develop or consolidate a renewed identity in the world, challenging their identity as being primarily highly valued their involvement in their mental health specific arts projects.

If we take a user-centred view of recovery, it is important to recognize the important part that the safety and mutual support offered by such projects can play in individual recovery journeys. As a number of service users have pointed out, people with mental health difficulties (or indeed other oppressed groups) do not necessarily want to be part of a mainstream society that has 
rejected them (Spandler 2007). Indeed, some participants appeared to be in the process of establishing a confident renewed identity that did not involve subscribing to mainstream social norms, but enabled them to accept and value themselves for who they were. It is important to recognize that social inclusion, in terms of integration in mainstream society, may not be lacking for some arts project participants, and may not be desirable for others.

While the participants in the Asian Women's project did report a number of benefits of arts participation, there was less emphasis on elements that directly related to notions of recovery as discussed here. In general, we should avoid drawing any simplistic conclusions from this observation, but there are a variety of possible interpretations. First, our interviews with these participants were primarily carried out with the aid of an interpreter and there may have been some issues in interpretation of keywords and phrases that did not resonate with our own understandings of these concepts.

Thus, we may have 'missed' references to these themes in these women's accounts. Second, it may not have been a key process for women using this project. Indeed, most of these participants specifically referred to the importance of their arts sessions as being 'time out' from the stresses and strains of their everyday lives and familial caring responsibilities. They often used art as a 'distraction' to focus themselves away from their lives, rather than rebuilding their lives. While they enjoyed the art sessions, the women often valued learning something new and gaining mutual support from each other. Finally, it could mean that these aspects of recovery are less important to South Asian women, although we would be especially cautious about this interpretation. More generally, it raises important issues regarding the importance of art and creativity in diverse communities, the applicability of what are currently primarily white Western notions of recovery to minoritized or diverse ethnic populations and the specific role and impact of cultural or gender-specific initiatives.

D. W. Winnicott argued that it is the inability to be creative and the living of one's life according to others' demands and requirements which often results in psychiatric problems as 'compliance carries with it a sense of futility ... and is associated with the idea that nothing really matters and that life is not worth living' (Winnicott 1991, p. 65).
[T] he link can be made . . . between creative living and
living itself, and the reasons can be studied why it is that
creative living can be lost and why the individual's
feeling that life is real or meaningful can disappear
(Winnicott 1991, p. 69).

Conversely, he argued that the ability to be creative instills a greater sense of the meaningfulness of life and this gives an individual greater individual 
agency and hope. It seems to be this sense of 'life worth living' that was one of the most important contributions made by the arts projects in our study. While we could debate the universality of creativity, or our understanding of 'recovery', the ability to have some control over one's actions does seem to be an important human requirement and was also an important facet in the reported benefits of arts participation.

While there was less evidence of 'recovery talk' among participants in some of the projects, the sense of freedom and control offered by their involvement in art was important, especially for women, whose lives were often dominated by caring responsibilities and the expectations and demands of others. In the context of a growing international recovery movement and increasing interest in the importance of hope and health (Parse 1999), it may be that arts initiatives have an important role to play.

However, the evidence-based practice agenda clearly poses a number of challenges for arts initiatives. For example, despite general agreement about the common features of 'recovery', there remain qualities that are particularly hard to standardize, define and measure (Bracken \& Thomas 2004, Wallcraft 2005). Although there have been attempts to measure some of these components, for example 'hope' (e.g. Miller \& Powers 1988, Herth 1991), research has tended to focus on clinical or 'hard' outcomes rather than more on these nebulous and elusive concepts which are highly subjective and do not in themselves have to relate to specific outcomes in order to be extremely important and beneficial to the individual.

In addition, it is clear that recovery, however defined, should be seen as an ongoing process, not as an outcome (Ralph \& Corrigan 2005). In this way, the understanding of various aspects of 'distance travelled' towards individual service user-defined outcomes should be among the criteria in evaluating the impact of arts projects. However, these should be flexible enough both to take into account the individuals' changing aspirations and to prioritise the aspects of life that they may particularly value.

\section{Conclusion}

While creativity might be viewed as an essential human need, not everyone will find a route to recovery through arts participation. Despite the importance of arts participation for many of the individuals involved in our case studies, we cannot necessarily assume this is a universal facet of recovery. Art may be important for some people, but arts participation (or for that matter involvement in any other activities) should not be predetermined as 'good for' people with mental health needs and thereby imposed on them (Repper \& Perkins 2003).

However, our study suggests that arts participation may be one important element of recovery for mental health service users who have found their lives caught up in a cycle of hopelessness and despair. For many of our interviewees, engaging in creative activities helped to reverse an enduring sense of hopelessness, despair and futility about the future, which can be common in people who are long-term users of mental health services. 
Therefore, we suggest that a recovery approach to mental health must recognize the potential contribution of arts and creativity. Moreover, specific arts and mental health provision may have an important role to play in the future of mental health and social care provision.

\section{Acknowledgments}

The research was jointly commissioned and funded by the Department for Culture, Media and Sport and the Department of Health. The views expressed are the authors' and do not necessarily reflect those of the funders.

\section{References}

Adams S.A. \& Partree D.J. (1998) Hope: the critical factor in recovery. Journal of Psychosocial Nursing 36, 29-32.

Aguilar E.J., Haas G. \& Manzanera F.J. (1997) Hopelessness and first episode psychosis: a longitudinal study. Acta Psychiatrica Scandinavica 96, 25-30.

Beck A.T., Brown G., Berchick R.J., et al. (1990) Relationship between hopelessness and ultimate suicide: a replication with psychiatric outpatients. American Journal of Psychiatry 147, 190-195.

Beresford P. (2000) What have madness and psychiatric system survivors got to do with disability and disability studies?

Disability and Society 15, 167-172.

Bracken P. \& Thomas P. (2004) Hope. Openmind 130, 10.

Coleman R. (1999) Recovery: An Alien Concept? Gloucester, Handsell.

Deegan P. (1988) Recovery: the lived experience of rehabilitation.

Psychosocial Rehabilitation Journal 11, 11-19.

Deegan P. (1990) Spirit Breaking: When the Helping Profession

Hurts. Routledge, New York, NY.

Drake R. \& Cotton P. (1986) Depression, hopelessness, and suicide in chronic schizophrenia. British Journal of Psychiatry

148, 554-559.

Dunn S. (1999) Creating Accepting Communities - Report of the MIND Inquiry into Social Exclusion and Mental Health Problems. MIND, London. 
Hacking S., Secker J., Kent L., et al. (2006) Mental health and arts participation: the state of the art in England. The Journal of the Royal Society for the Promotion of Health 126, 121-127. Heenan D. (2006) Art as therapy: an effective way of promoting positive mental health? Disability and Society 21, 179-191. Herth K. (1991) Development and refinement of an instrument to measure hope. Scholarly Inquiry for Nursing Practice 5, 39-51. Howarth C. (2003) Identity in whose eyes? The role of representations in identity construction. Journal for the Theory of Social Behaviour 32, 145-162.

Miller J.F. \& Powers M.J. (1988) Development of an instrument to measure hope. Nursing Research 37, 6-10.

Onken S., Dumont J., Ridgway P., et al. (2002) Mental Health Recovery: What Helps and What Hinders? National Technical Assistance Center for State Mental Health Planning, Alexandria, VA.

Parse R.R. (1999) Hope: An International Human Becoming Perspective. Jones and Bartlett Publishers, Sudbury, MA.

Pitt L., Kilbride M., Nothard S., et al. (2007) Researching recovery from psychosis: a user-led project. Psychiatric Bulletin 31, 55-60.

Ralph R.O. \& Corrigan P.W., eds (2005) Recovery in Mental Illness: Broadening Our Understanding of Wellness. American Psychological Association, Washington, DC.

Ramon. S. (2003) Users Researching Health and Social Care: An Empowering Agenda? Venture Press, Birmingham.

Repper J. \& Perkins R. (2003) Social Inclusion and Recovery: A Model for Mental Health Practice. Bailliere Tindall, London.

Ridgway P. (2001) Re-storying psychiatric disability: learning from first person recovery narratives. Psychiatric Rehabilitation Journal 34, 335-343.

Russinova Z. (1999) Providers' hope-inspiring competence as a factor optimizing psychiatric rehabilitation outcomes. Journal 
of Psychiatric Rehabilitation 16, 50-57.

Secker J., Hacking S., Spandler H., et al. (2007) Mental Health,

Social Inclusion and Arts: Developing the Evidence Base.

National Social Inclusion Programme, Care Services Improvement

Partnership, London.

Secker J., Spandler H., Kent L., Hacking S. \& Shenton J. (2008)

Empowerment and arts participation for people with mental health needs Journal of Public Mental Health. 6(4) 14-23

Spandler, H. (2007) From Social Exclusion to Inclusion? A Critique of the Inclusion Imperative in Mental Health Medical Sociology online 2(2): 3-16

Turner-Crowson J. \& Wallcraft J. (2002) The recovery vision

for mental health services and research: a British perspective.

Psychiatric Rehabilitation Journal 25, 245-254.

Wallcraft J. (2005) Recovery form mental breakdown. In: Social

Perspectives in Mental Health (ed Tew, J.), pp. 200-215. Jessica

Kingsley, London.

Winnicott D.W. (1991) Playing and Reality. Routledge, London. 